\title{
AS HISTÓRIAS E CULTURAS INDÍGENAS E AS AFRO-BRASILEIRAS NAS AULAS DE MATEMÁTICA
}

\author{
Wanderleya Nara Gonçalves Costa*
}

RESUMO: Inicialmente, é evidenciada a necessidade de implementação da Lei 11.645/08, que torna obrigatória a abordagem escolar das histórias e das culturas negras e indígenas. Em seguida, defende-se que: ressaltar tais culturas e histórias não implica vê-las fechadas em si mesmas; não é necessário estabelecer oposição frontal entre brancos, negros e índios; importa evidenciar o silenciado, os mecanismos de dominação e de exploração entre os grupos humanos e dissolver nossas certezas para que, ao descobrirmos outros significados, desconstruamos nossas percepções e categorizações, tornando-nos mais capazes de abordar tais histórias e culturas. Restringindo a discussão para a área de Educação Matemática, esses tópicos são, então, discutidos a partir dos referenciais da Etnomatemática, da História Cultural e dos Estudos do Imaginário. Finalmente, nesse contexto, é apresentado um breve estudo do maracatu para sugerir aos professores algumas possibilidades de ação.

Palavras-chave: Formação de Professores; Culturas Indígenas; Culturas Negras.

\section{INDIANS AND AFRO-BRAZILIANS HISTORIES AND CULTURE IN MATHEMATICS LESSONS}

ABSTRACT: Initially the necessity of implementation of the Law 11,645/08 is evidenced, which determines the approach of histories and the black and Indians cultures in the basic schools. After that, the arguments are presented: these histories and cultures are not close in itself; it is not necessary to establish a frontal opposition among white, black and Indians ; it matters to evidence the silenced one, the mechanisms of domination and exploration in human groups and, when discovering other meanings, we are becoming capable for approaching such histories and cultures. Shortening the discussion on the mathematical area, these arguments are discussed based on the use of Ethnomatematics, Cultural History and the Imaginary Studies. Finally, in this context, is presented a short study of Maracatu in order to suggest some possibilities of action to the teachers.

Keywords: Formation of Professors; Aboriginal Cultures; Black Cultures.

* Professora da Universidade Federal de Mato Grosso, Campus do Araguaia. Membro do Grupo de Estudos e Pesquisas sobre Etnomatemáticas Negras e Indígenas GEPENI/UFMT e do Grupo de Estudo e Pesquisa em Etnomatemática - GEPEm/ FEUSP.E-mail:wannara@ufmt.br 


\section{ANTECEDENTES}

$\mathrm{Na}$ tentativa de compreender os processos de produção de diferentes saberes relativos a quantificação, contagem, inferência, localização espacial, localização temporal e classificação, bem como a diversidade de pensamentos a respeito da educação e da matematização, é que, ao longo dos últimos anos, tenho empreendido pesquisas que privilegiam, sobretudo, saberes de origem indígena e negra. Nessa busca, enfoquei, principalmente, as relações existentes entre os mitos de diferentes povos e suas concepções de tempo, espaço e número. Ao fazêlo, concluí que a escola e a matemática veiculam — além de conhecimentos - valores, crenças, mitos, símbolos e representações, entre outros. Percebi, ainda, que os mitos fundantes de diferentes povos revelam cosmovisões diversas, capazes de gerar diferentes maneiras de pensar, sentir, atuar e matematizar. Por sua vez, tal fato acarretou a desconstrução de algumas certezas sobre os modos, conscientes e inconscientes, como reproduzimos técnicas de dominação da nossa própria cultura na relação com as outras. Isso levou-me, finalmente, a pensar sobre as possibilidades pedagógicas das festas populares - como expressões de histórias míticas e ritos — na implementação da Lei $11.645 / 08$.

A Lei 11.645/08 substituiu, complementando, a de número 10.639/03, que alterou a Lei de Diretrizes e Bases da Educação Nacional de 1996 (LDB), incluindo no currículo oficial dos estabelecimentos de ensino básico das redes pública e privada a obrigatoriedade do estudo da história e da cultura afro-brasileira. Com essa complementação, tornaramse também obrigatórias aulas sobre as histórias e as culturas dos povos indígenas. Não se trata de mais uma disciplina no currículo escolar, mas de uma orientação para que todas as disciplinas que constituem o currículo escolar básico — inclusive a matemática — incorporem a discussão sobre a contribuição dos negros e dos índios à cultura brasileira.

Foram a aprovação dessa lei, minha atuação na formação de professores e meus antecedentes como pesquisadora que me conduziram ao desenvolvimento de uma investigação em torno da seguinte questão: Que potenciais, tensões e desafios estão presentes na proposta de se ressaltar, no ensino de matemática nas escolas básicas, as culturas indígenas e afro-brasileira? Para abordá-la, listamos ${ }^{1}$ os seguintes 
objetivos: 1) Resgatar anterioridades sobre a presença do ser negro, do ser índio e de seus conhecimentos nas propostas de governo e nas pesquisas acadêmicas em Educação Matemática; 2) Descobrir como as categorias analítico-descritivas cultura negra, culturas indígenas, conhecimentos etnomatemáticos afro-brasileiros e indígenas são compreendidas e abordadas pelos professores de matemática da escola básica; 3) Sistematizar as possibilidades de uso pedagógico de etnomatemáticas indígenas e negras apontadas nas pesquisas, intensificando-as por meio da produção e da divulgação de conhecimentos e atividades didáticas capazes de auxiliar os professores de matemática a implementar ações de valorização das culturas indígenas e afro-brasileiras na escola.

É no âmbito desse último objetivo que encaminharei este trabalho, mas não pretendo, aqui, divulgar atividades didáticas relacionadas aos saberes negros e indígenas. Isso será feito, como prevê nosso projeto, em cursos de extensão a serem oferecidos a professores da escola básica. A intenção agora é explicitar os princípios que têm orientado a equipe na produção dessas atividades para, ao compartilhar ideias, estabelecer um diálogo que talvez nos permita vislumbrar possibilidades outras, além daquelas que hoje estão se constituindo.

Para tanto, inicialmente, comentarei o posicionamento que temos tomado frente às seguintes questões: na abordagem das culturas e das histórias indígenas, africana e afro-brasileira, que concepção de cultura adotaremos? O que falaremos sobre as culturas negras e indígenas? Que história contaremos? O que compreendemos por etnomatemática e qual deverá ser a sua contribuição?

Quanto à cultura, Certeau nos ensina que:

(...) de um lado é aquilo que "permanece"; do outro, aquilo que se inventa. Há, por outro lado, as lentidões, as latências, os atrasos que se acumulam na espessura das mentalidades, certezas e ritualizações sociais, via opaca, inflexível, dissimulada nos gestos cotidianos, ao mesmo tempo os mais atuais e milenares. Por outro lado, as irrupções, os desvios, todas essas margens de uma inventividade de onde as gerações futuras extrairão sucessivamente sua "cultura erudita". A cultura é uma noite escura em que dormem as revoluções de há pouco, invisíveis, encerradas nas práticas, mas pirilampos, e por vezes grandes pássaros noturnos, atravessam-na: aparecimentos e criações delineiam a chance de um outro dia. (CERTEAU, 1994, p. 239) 
Essas características de uma cultura também são ressaltadas por Geertz (1989, p. 15), para quem "o homem é um animal amarrado a teias de significados que ele mesmo teceu”. Esse autor diz que a cultura pode ser compreendida "como sendo essas teias e a sua análise; portanto, não como uma ciência experimental em busca de leis, mas como uma ciência interpretativa, à procura do significado" (GEERTZ,1989, p. 15). Explicitando melhor sua concepção de cultura, Geertz pontua que ela

denota um padrão de significados transmitidos historicamente, incorporado em símbolos, um sistema de concepções herdadas expressas em formas simbólicas por meio das quais os homens comunicam, perpetuam e desenvolvem seu conhecimento e suas atividades em relação à vida. (GEERTZ,1989, p. 103).

Nessa perspectiva, pensamos que as culturas dos povos negros e as indígenas podem ser estudadas segundo um ponto de vista histórico no qual as trocas culturais sejam analisadas a partir da ênfase entre algumas relações suas com a matemática escolar. Esse nosso posicionamento leva à assunção da postura de que ressaltar tais culturas não implica vê-las como fechadas nelas próprias e, menos ainda, como incólumes aos efeitos da modernidade. Significa também considerarmos que, ao tratarmos das histórias dos negros, dos índios e dos brancos, não é necessário estabelecer oposição frontal entre eles. Para nós, importa evidenciar o silenciado, o invisível, os mecanismos de dominação e de exploração entre os grupos humanos e dissolvermos nossas certezas para que, ao descobrirmos outros significados, desconstruamos nossas percepções e categorizações, tornando-nos mais capazes de abordar, nas aulas de matemática, as histórias e culturas afro-brasileiras e indígenas. É, então, que se torna imprescindível refletir sobre "qual história contaremos".

A chamada História Cultural é um ramo da História que tem empreendido um diálogo profícuo com a Antropologia e, nesse contexto, os símbolos, as imagens, as mentalidades e as práticas culturais são consideradas como acontecimentos que podem ser estudados para responder a questões do tipo: como se constituíram os mecanismos de dominação e de exploração entre os grupos humanos? Como esses mecanismos, no que se refere à constituição cultural de um povo, se difundem, se confrontam e se perpetuam? Para responder a tais questões, os historiadores dessa vertente dedicam-se, inclusive, ao estudo de 
representações e imaginário de um grupo, nas suas diferentes manifestações, por exemplo, nas pinturas, nas músicas e, principalmente, nos ritos.

Devido a essas características, a História Cultural tem-nos auxiliado a sugerir caminhos para, nas aulas de matemática, abordar as culturas e as histórias indígenas e afro-brasileiras. Ao buscar esses caminhos, não esquecemos as orientações de Gomes e Silva (2006), na sua afirmação de que pensar a diversidade étnico-cultural na formação de professores implica considerar os sujeitos e suas vivências nos processos históricos e socioculturais que ocorrem dentro e fora do contexto escolar. Também nessa busca e em consonância com a própria História Cultural e com as práticas educativas tradicionais negras e indígenas, lembramos que, segundo Durand (1996), história e mitos podem ser compreendidos como narrativas que se entrecruzam, imbricam-se, confundem-se, fundamentam-se ou limitam-se.

Essa maneira de conceber a relação entre história e mito nos tem sido útil para pensar sobre a abordagem escolar das culturas indígenas e afro-brasileiras, a partir, também, das considerações de Bâ na sua afirmação de que:

Na cultura africana, tudo é "História". A grande História da vida compreende a História da terra e das Águas (geografia) a História dos vegetais (botânica e farmacopéia), a História dos "Filhos do seio da Terra" (mineralogia e metais,) a História dos astros (astronomia, astrologia), a História das águas, e assim por diante. [...] Por exemplo, o mesmo velho conhecerá não apenas a ciência das plantas (as propriedades boas e más de cada planta), mas também "as ciências da terra" ( as propriedades agrícolas ou medicinais dos diferentes tipos de solo), a ciência das águas, astronomia, cosmogonia, psicologia, etc. Trata-se de uma ciência da vida, cujos conhecimentos sempre podem favorecer uma utilização prática. E quando falamos de ciências “iniciatórias" ou ocultas, termos que podem confundir o leitor racionalista, trata-se sempre, para a África tradicional, de uma ciência eminentemente prática que consiste em saber como entrar em relação apropriada com as forças que sustentam o mundo visível, e que podem ser colocadas a serviço da vida. (BÂ, 1982, p. 195)

Assim, o autor nos diz que a Geografia, a Botânica, a Mineralogia, a Astronomia, a Astrologia, a Psicologia e a Cosmologia, entre outras, podem ser compreendidas no contexto da grande "História da vida”, deixando-nos frente à questão: e os saberes matemáticos, também 
podem ser assim compreendidos e abordados? Podem eles ser vistos como constituintes desse tipo de ciência capaz de dialogar com os mitos dos quais Bâ nos fala? Mas observemos que talvez isso que Bâ chama de "grande história da vida" se assemelhe ao que, segundo Rocha e D’Urço (2008), o índio Kanátyo Pataxó pontua sobre o aprendizado nas culturas indígenas, a partir da integração entre os seres humanos e a natureza. É, segundo o Pataxó, na sua relação com o mundo que o índio aprende, inclusive a matemática, e cita como exemplo a adição:

Eu vou te dizer. Por exemplo, quando o cipó se abraça a uma árvore, ele tá fazendo a adição do amor. $\mathrm{E}$ isso quer dizer que ele se abraçou pra fazer um só corpo. A árvore e o cipó se abraçaram pra se tornar em um só corpo. Quer dizer que um pertence a dois e dois pertence a um. Formaram um corpo só, fizeram a adição do amor. E fizeram isso pra sobreviver um ao outro. Tem planta que precisa da outra pra sobreviver. Então isso é matemática. E também a matemática faz igualar tudo na natureza. $\mathrm{O}$ amor da Natureza iguala tudo. Quer dizer que se tem um amor na Natureza, sempre vai ter espaço para mais uma planta que vier. Vamos dizer que dá uma fruteira aqui e ali amadurece as frutas e uma paca vai lá e come uma fruta, lá adiante ela deixa o caroço. Lá nasce. Pode, tá cheio, mais ali sempre vai haver ali a Natureza, ela tá com o coração dela aberto. A Natureza tem o coração de mãe, sempre na casa dela, sempre cabe o lugar para mais um. Isso é matemática e isso é valor. (ROCHA; D’URÇO 2008, p. 1)

Percebemos daí a veracidade daquilo que Costa (2007) já apontava: que as maneiras utilizadas pelos diferentes povos para contar, classificar, localizar-se espacial e temporalmente, entre outros, estão fortemente relacionadas aos seus mitos e ritos. Note-se que Kanátyo Pataxó expõe uma concepção de matemática que não se identifica com aquela com a qual geralmente tomamos contato na escola, mas que se torna perfeitamente compreensível no âmbito das etnomatemáticas. Percebemos aí a reafirmação de que o Programa Etnomatemática pode ser uma opção valiosa para que os professores da área construam práticas capazes de ressaltar as histórias e culturas negras e indígenas.

D’Ambrosio (2001) usa o termo "Programa Etnomatemática" para referir-se a um programa de pesquisa que busca o conhecimento e a compreensão dos modos de geração, transmissão, institucionalização e difusão de conhecimentos. Por sua vez, uma etnomatemática vem sendo compreendida pela nossa equipe como um conjunto de ideias, conhe- 
cimentos e fazeres - relativos à classificação, à inferência, à ordenação, à explicação, à modelação, à contagem, à medição e à localização espacial e temporal — que se origina, "vive" e se renova a partir das necessidades que um grupo de pessoas sente de sobrevivência e transcendência. Essas necessidades ocorrem num contexto histórico e cultural indissociável da linguagem utilizada pelo grupo, dos códigos de comportamento adotados, das práticas sociais, dos valores, dos mitos e ritos, dos conhecimentos modificados ou apreendidos por meio da dinâmica cultural do encontro, das relações de poder que se estabelecem entre o grupo e a natureza, entre as pessoas do próprio grupo e entre o grupo e outros grupos, da arte e da religiosidade do próprio grupo, bem como de outros conhecimentos e manifestações culturais compartilhados por membros seus ${ }^{2}$.

Entendemos que a matemática também é um conjunto de conhecimentos relativos à classificação, à inferência, à ordenação, à explicação, à modelação, à contagem, à medição e localização espacial e temporal. Entretanto, ela faz uso, necessariamente e sempre, de uma linguagem artificial que se afasta da linguagem cotidiana, além de implicar provas e demonstrações. Essas suas especificidades têm feito com que a matemática seja compreendida como um tipo especial de etnomatemática. Mas esta, constituída por contribuições advindas de várias culturas, ganhou o status de universal e tornouse fundamento para a ciência e para a vida moderna, sendo considerada muito importante para a educação escolar de praticamente todos os povos, e não sendo chamada de "uma etnomatemática", mas de matemática.

Desse modo, enquanto as (outras) etnomatemáticas são consideradas como conhecimentos locais, em geral importantes somente no contexto em que são utilizadas, o mesmo não ocorre com a matemática por essa razão, as (outras) etnomatemáticas não fazem parte da cultura escolar mais geral. Mesmo no contexto da aplicação da Lei 11.645/08, seria difícil pensarmos em ensinar/estudar, com alguma profundidade, as etnomatemáticas negras e as indígenas nas escolas básicas. Isso porque se, no Brasil, existem mais de duzentos povos indígenas, há que se pensar que existe igual número de etnomatemáticas indígenas. Afirmação similar pode-se fazer em relação às etnomatemáticas negras, quando lembramos toda a diversidade cultural africana, bem como as diferentes origens daqueles que aqui foram escravizados.

Contudo, vale mencionar as contribuições que o Programa Etnomatemática tem trazido para a questão, desde a aprovação dos 
Parâmetros Curriculares Nacionais, visto que, de certo modo, a Lei 11.645/08 é uma tentativa de implementar modificações que os PCN's, por meio do Tema Transversal "Pluralidade Cultural", pouco conseguiram.

É verdade que professores/pesquisadores em Etnomatemática, mesmo antes da aprovação dos PCN's, sugeriram que os livros didáticos fossem modificados ou mesmo que fossem escritos livros paradidáticos para que o conhecimento indígena pudesse estar presente na escola do não-índio. Argumentando nesse sentido, Ferreira (1994) lembrou que tem sido, até certo ponto, comum que livros didáticos tragam informações sobre numerações egípcia, babilônia, romana e mesmo maia, mas silenciem quanto à numeração dos povos indígenas brasileiros. Então, ele sugeria que, por exemplo, poder-se-ia fazer constar nos livros a concepção de frações para os Krahó, a importância das diagonais nos retângulos para os Tapirapés e a simetria de rotação na pintura corporal dos Kadawel, entre outros.

É mister reconhecer, então, que, na época da aprovação dos PCN's, as etnomatemáticas indígenas já constituíam foco de várias pesquisas - entre as quais estão Amâncio (1999), Bello (1995; 2000), Correa (2001), Scandiuzzi (1997; 2000) e Mendes (1995; 2001) — e que a proposta de Ferreira seria exeqüível, mas isso não ocorreu em grande escala e, em geral, nas escolas não-indígenas, na exploração do tema Pluralidade Cultural, pouco se fez.

$\mathrm{Na}$ ocasião, foram veiculadas, entre os professores de matemática, apenas algumas atividades que procuravam, de modo ainda insipiente, considerar as culturas indígenas. É o caso, por exemplo, do uso de algumas pinturas corporais ou trançados de peneiras e esteiras para o estudo da geometria plana ou mesmo da adaptação do célebre problema das sete pontes de Königsberg ${ }^{3}$, em que as pontes passaram a ser sete aldeias de diferentes povos xinguanos. Nessas atividades, como em outras do gênero, não havia maior comprometimento com discussões sobre o papel social dos povos indígenas no Brasil, mas, pelo menos, à abordagem "tradicional" dos conteúdos da matemática escolar foram acrescentadas algumas informações sobre eles.

Por sua vez, as etnomatemáticas negras não constituíam, antes da aprovação da Lei 10.639/03, foco de pesquisas acadêmicas e, somente mais tarde, em decorrência desta, foi possível observar algumas tentativas mais efetivas de abordar as histórias e as culturas africanas e afro-brasileira 
na aula de matemática. Então, por exemplo, alguns professores passaram a utilizar as pinturas das casas ndebeles para o ensino da geometria plana ${ }^{4}$, visto que as paredes internas e externas de tais casas são pintadas pelas mulheres desse povo africano com desenhos gráficos coloridos, cujos padrões são compostos, principalmente, a partir de figuras geométricas. Nesse caso, a beleza e a riqueza dessas pinturas as tornaram atrativo para professores de matemática que procuram, de algum modo, abordar a cultura africana. Mas, novamente, as atividades não incitavam uma discussão maior sobre o papel dos africanos na constituição do povo e da cultura brasileiros.

Entretanto, mesmo não identificando os conhecimentos geométricos negros e os indígenas como etnomatemáticas, Gaspar (2003) traz algumas análises sobre eles, apresentando sugestões para seus estudos na formação de professores. Embora, nesse trabalho, também não se possa identificar maior preocupação com questões políticas ou de resistência, ele constitui importante fonte de pesquisa para aqueles que se dispõem a ressaltar, no ensino de geometria, tanto as culturas indígenas quanto as africanas.

Posteriormente, Costa e Silva (2005), voltando-se para a abordagem da cultura afro-brasileira nas aulas de matemática, sugeriram o uso da capoeira e do jogo de búzios. A primeira atividade, segundo eles, poderia ser utilizada no ensino de geometria plana e espacial, enquanto a segunda seria mais afeita à probabilidade. Esse trabalho, apesar de pouco mostrar em relação às diferentes formas utilizadas pelos negros para contar, medir, localizar-se, entre outros, pelo menos tratou do problema de imprimir à matemática escolar ações de valorização de símbolos representativos da cultura negra, a partir de alguma discussão sóciohistórico-política. Ainda no que se refere à abordagem das culturas negras, nas aulas de matemática, foi apresentado por Santos (2008) um trabalho no qual os tecidos de Gana servem como pretexto para o aprendizado conjunto da matemática escolar - geometria, principalmente - e cultura africana.

De todo modo, ainda são poucas as contribuições que os professores de matemática do ensino básico de todo o país têm recebido para abordar as culturas dos povos indígenas e negros. Urge, pois, encontrar caminhos que nos levem a adotar práticas pedagógicas que respeitem e divulguem a diversidade das culturas negras e das indígenas. 
Particularmente, penso que a contribuição que o Programa Etnomatemática traz à questão pode dar-se, principalmente, a partir de dois caminhos. O primeiro deles, discutido em Costa (2007), refere-se à difusão de conhecimentos capazes de levar professores e alunos a perceberem que existem diversas concepções de número, diferentes modos de contagem, de organização espacial e temporal - embora apenas uma delas seja a divulgada/valorizada pela escola, devido a questões de poder e de interesse de alguns grupos — e, a partir daí, sugerir a adoção de algumas posturas.

Outra contribuição possível é a utilização da experiência adquirida em olhar para múltiplas culturas, tendo como foco os diferentes modos de matematizar, para encontrar e difundir maneiras mais efetivas de estabelecer algumas relações entre a matemática escolar e as histórias e culturas africana, afro-brasileira e indígena. É nessa vertente que se inclui a proposta da equipe que integro na busca por analisar as possibilidades pedagógicas das festas populares - enquanto ritos e expressão de histórias míticas — na implementação da Lei 11.645/08.

\section{OS MITOS, OS RITOS, AS FESTAS E SUAS POSSIBILIDADES PEDAGÓGICAS}

Tanto em comunidades indígenas quanto em quilombolas, geralmente, os mitos são considerados os discursos verdadeiros, que são aqueles que se deve respeitar. Neles está impresso - ou talvez expresso - o conhecimento dos ancestrais. Mas é por meio dos ritos que as pessoas incorporam os mitos e também os atualizam, assim, transcendem ao imediato vivido, renovam suas forças e estabelecem relações com o sagrado. Enquanto os mitos rememoram a acontecimentos, os ritos os comemoram, por essa razão, muitos ritos são chamados de festas.

Entretanto, mitos e ritos/festas indígenas ou negros não estão estagnados, visto que são prenhes de significados que os levam a agregar novas possibilidades interpretativas. Ao serem transformadas, tais histórias passam a considerar experiências vivenciadas por diversas pessoas na busca pela compreensão do mundo sempre em construção, pois, se ouvirmos, ao longo dos tempos, um mesmo mito, por vezes é possível observarmos traços diferentes que estão em consonância com problemáticas nascentes em determinada época. 
Sejam elas contadas por meio da palavra ou vivenciadas por meio de ritos - quase sempre denominados de festas —, as histórias míticas sugerem forma e sentido, significado e orientação para a vida dos jovens, educando-os. Entretanto, é comum que essa maneira de educar seja desconsiderada nas nossas escolas, em que se assume, erroneamente, que deve haver uma separação entre o mythos e o logos, entre conhecimentos tradicionais e ciência, entre o antigo e o novo. Contudo, Pessoa (2007, p. 3) argumenta que as festas podem ser pensadas como experiências educativas, situações de aprendizagem, e afirma que, para a maioria dos antropólogos, a festa é um tipo de ritual. Pessoa explica-nos ainda que

É dessa forma [por meio das festas] que o povo escreve suas memórias, seus valores, seus códigos de regras, suas crenças, suas angústias pelo árduo trabalho, suas esperanças e fantasias. Os ingredientes que compõem a festa popular são também textos por meio dos quais a gente simples manifesta tudo aquilo que lhe toca mais profunda e intensamente. (...) Conseqüentemente, podemos pensar a festa como uma grande escola, na qual se aprende, antes de outras tantas coisas, como a vida em sociedade acontece - seus valores, seus conflitos e suas possibilidades de interação e sociabilidade. (PESSOA, 2007, p. 4-5)

Berkenbrock (2002, p. 103) complementa: “a festa aponta para algo maior, está ligada a um significado superior ao que aparece. Ela tem sua fundamentação na própria compreensão do sagrado”. Mas é Pessoa (2007) quem sugere algumas formas de se utilizar, em ambiente escolar, as festas populares e, numa dessas indicações, diz que, depois de conhecida, determinada festa pode ser tomada também como situação de potencialização ou ampliação do conhecimento dos educandos sobre a diversidade cultural brasileira. Compreende-se, pois, que as festas que colocam em evidência danças coletivas podem ser vistas como fonte de aprendizagem escolar — sobretudo quando são exploradas na sua relação com os princípios da História Cultural. É nessa confluência que se torna mais verdadeira a afirmação de que:

é o mito que, de algum modo, distribui os papéis da história e permite decidir aquilo que "faz" o momento histórico, a alma de uma época, de um século, de uma idade da vida. (...) Ora, é o mito que é o referencial último a partir do qual a história se compreende, a partir do qual o "mister do historiador" é possível e não o inverso. O mito vai ao encontro da história, atesta-a e legitima-a, tal como o Antigo Testamento e as suas "figuras" garantem a 
autenticidade histórica do Messias para um cristão. Sem as estruturas míticas, a inteligência histórica não é possível. (DURAND, 1996, p. 87)

De toda forma, procurarei tornar mais claro o modo como, em nosso trabalho, temos evidenciado as relações entre os mitos e ritos negros e indígenas, com a sua história cultural e seus conhecimentos etnomatemáticos.

\section{E AS HISTÓRIAS SE ENTRETECEM...}

Embora seja verdade que as histórias e as culturas negras e indígenas difiram bastante entre si, em algumas formas de expressão cultural elas se "tocam". Essas expressões, de modo especial, têm se revelado, para nós, como interessantes maneiras de implementar a Lei 11.645/08, abordando, de forma conjunta, as culturas em questão.

Nosso interesse pela abordagem conjunta das etnomatemáticas, das histórias e das culturas negras e indígenas não se deve somente às dificuldades enfrentadas pelos professores - seja com relação a um tempo já escasso, até mesmo para tratar os conteúdos específicos da matemática, seja por falta de mais conhecimentos sobre os temas aos quais a Lei diz respeito. Essa forma de abordagem deve-se, principalmente, ao fato de que as identidades são relacionais e, por essa razão, um grupo humano é melhor compreendido tendo como "pano de fundo" um outro grupo (HALL, 2003).

Sobretudo, consideramos que essa forma de abordagem das histórias e das culturas indígenas e negras nas escolas incita o debate sobre a constituição das diferentes formas de dominação entre os grupos que deram origem ao povo e à cultura brasileiros - e o faz de modo que, ao fugir da armadilha dos discursos que fazem a apologia de uma democracia racial, não "derrape" para os discursos identitários ortodoxos, que não expressam a realidade brasileira, embora possam ser válidos para outros países. -

Observe-se, entretanto, que a abordagem conjunta das culturas negras e indígenas em ambiente escolar não é algo inusitado, pois algumas produções culturais, como as festas de congado, bumba-meu-boi e maracatu - que parecem condensar elementos culturais de matrizes negra e indígena, além de portuguesa — por vezes encontram espaço nas 
salas de aula. Contudo, na maioria das vezes, sua presença se limita às aulas de artes ou às festividades da semana do folclore. Assim, talvez seja uma inovação nossa proposta de levar para as aulas de matemática atividades elaboradas a partir de tais expressões culturais.

Faz-se necessário, contudo, ressaltar que, ao propor que, nas aulas de matemática, empreendamos um olhar para elementos da cultura popular, explicitando as trocas culturais, não estamos retomando o discurso de uma pacífica miscigenação que teria dado origem à cultura brasileira, mas é inegável que, por razões diversas, alguma influência cultural ocorreu entre índios, negros e brancos. Reconhecer esse fato, sua importância na constituição da nação brasileira e naquilo que consideramos expressões da cultura popular de nosso país, parece-nos fundamental para a valorização do ser negro e do ser índio.

Todavia, Amantino (2005) relata as dificuldades para encontrar elementos que permitam explorar as trocas culturais ao longo da história brasileira mais antiga, afirmando não existirem registros escritos a respeito de aspectos sociais, culturais e populacionais sobre os índios e os negros. A autora lembra que os diversos grupos, devido ao sistema escravista, mantiveram diferentes formas de relações sociais, pois, se alguns quilombos eram constituídos por negros e índios, também ocorria a incorporação de escravos africanos e afro-brasileiros a povoados indígenas. Não foram raras as ocasiões em que a condição comum de oprimidos e despossuídos contribuía para aproximá-los, mas também houve momentos e locais em que esses grupos disputaram, de forma violenta, território, uns procurando eliminar os outros. Por vezes, os índios, hábeis conhecedores da região, foram utilizados pelos donos de engenhos para caçar os negros escravizados, outras vezes o faziam por conta própria - em busca de recompensas.

Como enfatiza Amantino (2005), os índios, ao aprisionarem os negros e exigirem pagamento por esse serviço, adotavam um comportamento e lidavam com valores e conceitos da sociedade que os mantinha submissos. Para os senhores escravocratas e para as autoridades, a utilização dos índios como "capitães-do-mato" era interessante, não só pela experiência que eles tinham em movimentar-se na mata, mas porque esse fato também facilitaria, em momento oportuno, os processos de retirada dos próprios índios dessas regiões - principalmente por meio dos aldeamentos, nesses próprios locais ou em áreas mais afastadas. 
Assim, pode-se ver que os grupos indígenas e os quilombolas - por escolha própria ou não - mantiveram, quase sempre, contatos culturais nos momentos em que compartilharam uma mesma região. Entretanto, estes dois grupos também estiveram expostos à influência exercida pela cultura Cristã Ocidental. Havia, portanto, na Colônia, ainda que nos mais recônditos locais, a criação de culturas que abarcavam traços de origens variadas e que tanto sofriam influências quanto a exerciam sobre outras. (AMANTINO, 2005, p. 96)

A historiadora diz ainda que o resgate de tradições culturais negras ou indígenas tem acontecido por meio de análises iconográficas, mas ela enfatiza que tais fontes não captaram as trocas culturais travadas entre os grupos. Para "preencher essa lacuna", Amantino sugere que sejam utilizadas as danças coletivas, as festas - ou ritos - populares, com características culturais africanas ou indígenas.

Essa sua sugestão coadunou-se com as nossas intenções de utilizar, nas aulas de matemática, elementos míticos e rituais das culturas foco da Lei 11.645/08. Sentimo-nos, pois, amparados para explorar festas populares, de modo a utilizá-las no ensino conjunto de matemática, histórias e culturas afro-brasileiras e indígenas. De fato, devido à riqueza do patrimônio imaterial que tais festas constituem, nos vimos frente a várias possibilidades, entre elas, nos detivemos nos maracatus. Eles, em especial, evidenciam suas raízes africanas, indígenas e portuguesas e trazem alguns elementos que podem ser utilizados pelo professor de matemática para abordar também conteúdos específicos de sua disciplina.

\section{OS MARACATUS}

Os maracatus envolvem uma rede de mito e história, oferecendo espaço para as mais variadas manifestações pessoais e coletivas do povo brasileiro. Neles, assim como em outras festas populares, emergem as religiosidades, as formas como os colonizadores europeus, os africanos escravizados e os índios autóctones se relacionavam com o sagrado. Assim, os maracatus se caracterizam pela presença forte de sua origem mística, expressa, entre outros, pelas danças que remetem ao candomblé, além das performances especiais na frente das igrejas católicas, representando um "agrado" a Nossa Senhora do Rosário e a São Benedito. Realmente, não são poucos os pesquisadores que apontam suas 
origens nas festas católicas dedicadas aos Reis Negros, como a Festa do Rosário.

Mas, para compreender as diferentes influências artísticoreligiosas presentes nos maracatus, não basta dizer, por exemplo, que a população negra encontrou formas não só de integrar, mas também de maquilar sua religiosidade, fazendo corresponder seus orixás a santos católicos. Além disso, Gandon (1997) explica que:

(...) os jesuítas procuraram adaptar a arte européia ao contexto cultural dos índios brasileiros. Escrevendo em 1585, o padre Anchieta relatava que numa das três missões de índios cristãos livres, situadas na costa norte da Bahia Espírito Santo, São João e Santo Antonio - os padres ensinavam os índios a cantar, "e tem seu coro de canto e flautas para suas festas, e fazem suas danças à portuguesa com tamboris e violas, com muita graça, como se fossem meninos portugueses, e quando fazem estas danças põem uns diademas na cabeça de penas de pássaros de várias cores, e desta sorte fazem também os arcos, empenam e pintam o corpo”. Desde o século XVI, os jesuítas se serviam também dos autos -forma teatral de uma trama popular, com cantos e danças - como elemento eficaz da catequese. É bastante provável que, desde então, personagens representativos dos indígenas figurassem nestas peças, encenadas sobretudo no ciclo natalino.

O gênero popularizou-se. Para ele convergiram as danças dramáticas, algumas realizadas à portas ou adros das igrejas.

Com a chegada dos africanos, novos elementos vão ser introduzidos nas manifestações artísticas populares do Brasil. "O negro está nos congos. O português no fandango ou marujada. O mestiço, crioulo, mameluco, dançando, cantando, vivendo, está no Bumba-Meu-Boi, o primeiro auto nacional na legitimidade temática e lírica e no poder assimilador constante e poderoso", nos diz Câmara Cascudo. (GANDON, 1997, p. 156-157)

O maracatu teria sido criado pelos negros escravizados, por meio de modificações às festas católicas feitas com o objetivo de cultuar suas próprias entidades espirituais e, ao mesmo tempo, para servir-lhes com um "escape" para o sofrimento de que padeciam. As influências indígenas viriam mais tarde.

Maakaroum (2005), ao discutir as várias versões que explicam a origem do termo maracatu, apresenta a de Mário de Andrade, na qual a palavra teria sua gênese explicada da seguinte maneira: maracá = instrumento ameríndio de percussão; $c$ atu = bom, bonito em tupi; marã = guerra, confusão. Marãcàtú e, depois, maracatu, com o significado de guerra bonita - o que evidenciaria também uma influência indígena ${ }^{5}$. Além disso, 
em alguns maracatus, entre os personagens está a figura do caboclo de pena, que representa os índios brasileiros.

Note-se que existe mais de um tipo de maracatu: o Maracatu de Baque Virado ou Nação e o Maracatu de Baque Solto, também chamado de Maracatu de Orquestra ou Rural. Eles se diferenciam tanto pela origem quanto pelos instrumentos e toques musicais que utilizam, além de este último não possuir rei ou rainha.

O Maracatu de Baque Virado ou Nação tem como seguidores os devotos dos cultos afro-brasileiros da vertente Nagô e, nos cortejos, uma boneca chamada de Calunga encarna a divindade dos orixás. Outros personagens são: o rei, a rainha, a dama de honra da rainha, a dama de honra do rei, o príncipe, a princesa, o ministro, o embaixador, o duque, a duquesa, o conde, a condessa, os vassalos, as damas de paço (que portam as calungas durante o desfile do maracatu), o porta-estandarte (trajado à Luís XV), o escravo sustentando a umbrela ou pálio (chapéu-de-sol que protege o casal real e que está sempre em movimento), os animais, o guarda-coroa, o corneteiro, a baliza, o secretário, os lanceiros, o brasabundo (uma espécie de guarda-costas do grupo), os batuqueiros (percursionistas), as baianas e os caboclos de pena. Estes últimos, os representantes dos índios, dançam ao redor do cortejo, emitindo sons que lembram o de animais, imitando pássaros selvagens e produzindo estalos secos e rápidos com seus arcos e flechas.

Instrumentos como alfaias ${ }^{6}$, caixas e taróis, ganzás, gonguê ${ }^{7}$, xequerês ${ }^{8}$ e apitos — os últimos incorporados das tradições indígenas são usados na execução do maracatu, que se faz presente em vários estados do Brasil. Geralmente, os integrantes de um maracatu usam roupas especiais: os caboclos de lança utilizam mantos coloridos e a sua lança é enfeitada com fios luxuosos e compridos - um destaque especial são as "golas dos caboclos de lança" e, em algumas cidades nordestinas, existe concurso e premiação para os criadores de golas.

A tradição religiosa do maracatu - em especial relação com o candomblé e a umbanda - é mantida por muitos grupos, enquanto, para outros, ele vem se tornando apenas uma brincadeira carnavalesca. Isso nos revela que certas práticas podem mudar completamente de sentido, mas que, ainda assim, mantêm certos aspectos tradicionais que funcionam como elementos emblemáticos de uma identidade cultural. É isso que torna o maracatu, ainda hoje, um símbolo da cultura negra e, ao mesmo 
tempo, com a presença do caboclo de pena, revela as trocas culturais entre negros e índios.

Outras festas/ritos, como a congada ou o bumba-meu-boi, também são reveladoras das heranças culturais que recebemos dos negros e dos índios. Tais heranças, muitas vezes, passam praticamente desapercebidas. Problematizar esse fato, discutir os discursos e as várias técnicas de dominação étnico-raciais que permeiam nosso cotidiano, parece ser, hoje, um compromisso importante para educadores de todas as áreas - inclusive para o professor de matemática. Entretanto, sugere-se que este não o faça "à parte" dos conteúdos relacionados à sua disciplina. E para que festas como o maracatu tornem-se, também nas aulas de matemática, uma experiência educativa formal, tanto de conteúdos específicos da área quanto das culturas e das histórias negras e indígenas, os professores podem criar diferentes caminhos - adequados, inclusive, aos diferentes níveis e anos escolares. Por exemplo, temos sugerido a exploração das simetrias nas golas dos caboclos de lança. Enquanto, em séries superiores, isso pode ocorrer por meio de conceitos mais formais, crianças menores podem reproduzir, com papel colorido e vidrilhos, alguns desenhos mais simples.

Um olhar mais cuidadoso para as indumentárias dos personagens do maracatu permite a percepção de várias figuras geométricas planas, enquanto reproduções em sucata dos instrumentos de percussão utilizados no cortejo podem ser proveitosas para o estudo da geometria espacial. As próprias "saias de contas" dos xequerês nos trazem algo sobre a pavimentação de planos. O conceito de média pode ser explorado por meio do número de contas utilizadas para se fazer esse instrumento.

Como, no cortejo do maracatu, cada personagem tem seu lugar marcado, mas as pessoas representativas de cada um desses personagens podem mudar de lugar entre si, é possível explorar o conceito de permutação. Um estudo de regra de três e proporção pode se dar a partir de uma análise sobre a representatividade de cada um dos povos que originaram o povo brasileiro por meio dos personagens do cortejo.

O tema favorece o trabalho interdisciplinar, notadamente com professores de Artes, História, Geografia e Língua Portuguesa. Um trabalho de pesquisa realizado pelos educandos pode trazer informações sobre a existência de grupos de maracatu na região, bem como sobre outras festas/ritos por meio dos quais a comunidade onde a escola está 
inserida transmite suas memórias, crenças, esperanças e fantasias. Uma análise sobre essas festas é capaz de informar sobre valores, conflitos e histórias de interação entre os diferentes grupos de pessoas que contribuem com a constituição das expressões culturais da região e, ainda, uma forma própria de matematizar. Essas são apenas algumas possibilidades, muitas outras podem ser criadas. É importante, contudo, que esteja sempre presente a percepção de que

A dimensão educativa da festa expressa-se, especialmente, numa ambigüidade que lhe é intrínseca: a festa visa marcar em cada membro do grupo social os seus valores, as suas normas, as suas tradições; ao mesmo tempo em que se transforma sempre num grande balcão, numa grande demonstração das inovações, das mudanças, das novas descobertas, das novas concepções e, porque não dizer, da fecundidade das transgressões. Festejar ou simplesmente festar, como dizemos num genuíno "goianês", é, antes de tudo, aprender o quanto temos de riqueza e de sabedoria a preservar e, ao mesmo tempo, o quanto temos a aprender com as transformações da história, com a lenta mudança das mentalidades. Quem vai à festa tem a possibilidade de aprender que o que se sabe ainda não é tudo para se continuar a viver e a reproduzir as condições de sobrevivência. Há que se abrir para o novo que cedo ou tarde acaba chegando e preenchendo nossos espaços vitais, até mesmo os de nossa habitação. Mas na festa também se pode aprender que o novo, por mais irremediável que seja, precisa ser integrado à herança que recebemos, que foi e, em muitos casos, ainda permanece sendo reconstituída, reproduzida e ensinada por abnegados artistas e sábios conservadores da cultura popular. A festa popular é o grande e fecundo momento a nos ensinar que a arte de viver e de compreender a vida que nos envolve está na perfeita integração entre o velho e o novo. Sem o novo, paramos no tempo. Mas sem o velho nos apresentamos ao presente e ao futuro de mãos vazias. (PESSOA, 2005, p. 30)

E, sobretudo, devemos lembrar que esse "novo" que está sendo construído pode nos trazer outras formas de integração entre negros, índios e brancos - formas estas em que o modo de ser e saber de cada um seja respeitado e valorizado. Neste momento, cabe lembrar que alguns professores, devido às suas opções religiosas, por vezes sentem dificuldades em tratar de expressões culturais que, como o maracatu, trazem em si traços de diferentes religiões. Casos como esses requererão do professor um esforço maior para vencer a intolerância ou o preconceito, para que consiga impor a si mesmo uma postura de respeito não só à diversidade etnocultural, mas também religiosa do povo brasileiro. 


\section{UMA HISTÓRIA, UM RITO E AS \\ RESPOSTAS QUE DÃO ÀS NOSSAS PERGUNTAS}

Algumas das vivências educacionais mais profundas e significativas para as crianças ocorrem fora do espaço escolar, ao acompanharem festas populares que trazem em si marcas de diferentes culturas. Elas - ao contrário de algumas aulas que procuram "instrumentalizar" ou "capacitar" — buscam compartilhar pequenos detalhes de sabedoria, de experiências de vida e momentos de alegria. Essas expressões de cultura popular que educam para a vida lembram, a cada manifestação, os brancos, os negros e os índios brasileiros - tanto nos processos de resistência dos dois últimos grupos quanto nas diferentes trocas que estabeleceram ao longo da história brasileira entre europeus, africanos e povos autóctones. Por isso, a elas recorri para refletir sobre as possibilidades de implantação da Lei 11.645/08, no que se refere às aulas de Matemática.

A aplicação — o "fazer cumprir" — dessa lei, que é fruto de articulações de grupos de resistência e de valorização do ser negro e do ser índio, dependerá tanto das interpretações que dela serão feitas quanto do lugar político e ideológico que ocupará o professor da escola básica aquele que, em última instância, está dela encarregado. Daí a necessidade de problematizar concepções e preconceitos desses professores e, também, de auxiliá-los na construção de caminhos capazes de, inclusive nas aulas de matemática, abordar os saberes e fazeres negros e indígenas.

Para a construção de tais caminhos, penso ser necessário "sair dos trilhos", fazer fluir e produzir outras conexões, pois não haverá mudanças se não nos entregarmos às circunstâncias e aos desafios que o momento - e a Lei — nos impõe. Foi esse pensar que me conduziu a tomar aqui o maracatu como objeto de análise, para que, ao evidenciar o silenciado, o invisível, os mecanismos de dominação e de exploração entre grupos etnoculturais que ele abriga, pudéssemos também refletir sobre as possibilidades que apresenta para o ensino de matemática.

Ao fazê-lo, procurei ilustrar o fato de que, como todas as identidades, a do ensino de matemática também é múltipla. Ela pode ser reinventada a todo momento, notadamente quando reconhecemos que esse não é neutro, mas, sim, parte de um processo marcado por relações de diferença e de poder. 
Cabe lembrar que talvez o ensino de matemática não seja um elemento determinante para mudar relações entre negros, brancos e índios, mas, sem dúvida, qualquer mudança em um elemento que "faça parte desse jogo" pode abalar as estruturas existentes, contribuindo para o surgimento de uma nova ordem. Aí está o valor desse tipo de ação. Entretanto, ao final deste artigo, permito-me revelar minha crença de que a grande contribuição da Etnomatemática não está em apontar aos professores maneiras de estabelecer algumas relações entre a matemática escolar e as culturas africana, afro-brasileiras e indígenas. Penso que sua maior contribuição está naquele outro caminho que citei anteriormente que se refere à difusão de conhecimentos capazes de levá-los a tomarem consciência sobre os fundamentos classificatórios e os respectivos juízos de valor acerca das diferentes maneiras de classificar, inferir, ordenar, modelar, contar e medir, entre outros. Essa tomada de consciência é que poderá trazer mudanças mais profundas nas posturas dos professores, levando-os a problematizar não só essas práticas, mas também outras relacionadas aos preconceitos e às desvalorizações até hoje sofridas por negros e índios brasileiros. Mas, até lá, para construirmos os caminhos, coloquemos uma pedra por vez...

\section{REFERÊNCIAS}

AMANCIO, C. N. Os kanhgang da bacia do Tibagi: um estudo etnomatemático em comunidades indígenas. 1999. Dissertação (Mestrado em Educação Matemática) Instituto de Geociencias e Ciências Exatas, Universidade do Estado de São Paulo UNESP. Rio Claro, 1999.

AMANTINO, M. A convivência entre índios e negros nas dança folclóricas brasileiras: uma análise histórico-antropológica. In: LIGIERO Z.; SANTOS C. A. (Org.). Dança da Terra: tradição, história, linguagem e teatro. Rio de Janeiro: Papel Virtual, 2005, v. 1, p. 91-117. BÂ, H. A tradição viva. In: KI-ZERBO, J. (Org). História da África. São Paulo: Ática; Paris: Unesco, 1982.

BELLO, S. E. L. Educaşão Matemática indígena: um estudo etnomatemático com os índios Guarani-Kaiowá do Mato Grosso do Sul. 1995. Dissertação (Mestrado em Educação) Setor de Educação, Universidade Federal do Paraná/UFPR, Curitiba, 1995.

BELLO, S. E.L. Etnomatemática: relações e tensões entre as distintas formas de explicar e conhecer. 2000. Tese (Doutorado em Educação) Faculdade de Educação, Universidade Estadual de Campinas/UNICAMP, Campinas, 2000.

BERKENBROCK, V. J. A festa nas religiões afro-brasileiras - a verdade torna-se realidade. In: PASSOS, M. (Org). A festa na vida: imagens e significados. Petrópolis: Vozes, 2002. p. 191-221. 
BRASIL. Lei n. 11.645, de 10 março de 2008. Altera a Lei no 9.394 , de 20 de dezembro de 1996, modificada pela Lei n. 10.639, de 9 de janeiro de 2003, que estabelece as diretrizes e bases da educação nacional, para incluir no currículo oficial da rede de ensino a obrigatoriedade da temática "História e Cultura Afro-Brasileira e Indígena". Publicado no DOU de 11.3.2008. Disponível em <http://www.planalto.gov.br/ccivil_03/_Ato2007-2010/2008/Lei/L11645.htm>. Acessada em 03/05/2008.

CERTEAU, M. A invenção do cotidiano. Rio de Janeiro: Vozes, 1994.

CORREA, R. A. A Educação Matemática na Formação de Professores Indígenas: os Professores Ticuna no Alto Solimões. 2001. Tese (Doutorado em Educação) Faculdade de Educação. Universidade Estadual de Campinas - UNICAMP. Campinas, 2001.

COSTA, W. N. G. A etnomatemática da alma A'une-xavante em suas relações com os mitos. 2007, 270p. Tese (Doutorado em Educação, Área de Concentração: Ensino de Ciências e Matemática) Faculdade de Educação, Universidade de São Paulo. São Paulo, 2008.

COSTA, W. N. G.; SILVA, V. L. Matemática mítico-religiosa-corporal do negro brasileiro. Scientific American Brasil, São Paulo, p. 94-98, 2005. (Edição Especial Etnomatemática)

D’AMBROSIO, U. Etnomatemática - elo entre as tradições e a modernidade. Belo Horizonte: Autêntica, 2001.

DURAND, G. Campos do Imaginário. Lisboa: Instituto Piaget, 1996.

FERREIRA, E. S. A importância do conhecimento etnomatemático indígena na Escola dos não-índios. Em Aberto- Temas: Tendências na Educação Matemática, v. 62, p. 89-95, 1994.

GANDON, T. A. O índio e o negro - uma relação legendária. Revista Afro-Ásia, Salvador, UFBA, n. 19/20, p. 135-164, 1997.

GASPAR, M. T. J. Aspectos do desenvolvimento do pensamento geométrico em algumas civilizações e povos e a formação de professores. 2003. Tese (Doutorado em Educação Matemática) Instituto de Geociências e Ciências Exatas, Universidade do Estado de São Paulo - UNESP. Rio Claro, 2003.

GEERTZ, C. A interpretação das culturas. Rio de Janeiro: Guanabara, 1989.

GOMES, N. L.; SILVA, P. B. G. (Org.) Experiências étnico-culturais para a formação de professores. 2 ed. Belo Horizonte: Autêntica, 2006.

HALL, S. Da diáspora: Identidades e mediações culturais. Organização Liv Sovik; tradução Adelaine La Guardia Resende et all. Belo Horizonte: UFMG; Brasília: UNESCO/Brasil, 2003.

MAAKAROUN, E. F. Maracatu - Ritmos Sagrados. 2005. Dissertação (Mestrado em Artes Visuais) Escola de Belas Artes, Universidade Federal de Minas Gerais - UFMG. Belo Horizonte, 2005.

MENDES, J. R. Descompassos na interação Professor-Aluno na aula de matemática em contexto indígena. 1995. Dissertação de Mestrado. Instituto de Estudos Lingüísticos. Universidade Estadual de Campinas - UNICAMP. Campinas, 1995.

MENDES, J. R. Ler, Escrever e Contar: Práticas de Numeramento-Letramento dos Kaiabi no Contexto de Formação de Professores Índios do Parque Indígena do Xingu. Tese de doutorado. Instituto de Estudos Lingüísticos, Universidade Estadual de Campinas - 
UNICAMP. Campinas, 2001.

PESSOA, J. M. Saberes em festa: gestos de ensinar e aprender na cultura popular. Goiânia: Editora da UCG/Kelps, 2005.

PESSOA, J. M. Proposta Pedagógica: aprender e ensinar nas festas populares. BRASIL. Salto para o Futuro. Boletim 2, abril de 2007. Disponível em <www.tvebrasil.com.br/SALTO>. Acesso em maio de 2008.

ROCHA, J.; D’URÇO, I., 2008. Uma tarde ensolarada de amor. Disponível em <http://www.letras.ufmg.br/bay/sites/territorios/tarde.htm>. Consultado em maio de 2008. Com base em entrevista com Kanátyo Pataxó.

SANTOS, E. C. Os tecidos de Gana como atividade escolar: uma intervenção etnomatemática para a sala de aula. 2008. Dissertação (Mestrado em Educação Matemática) Pontifícia Universidade Católica de São Paulo, PUC/SP, Brasil. 2008.

SCANDIUZZI, P. P. A dinâmica da contagem de Lahatua Otomo e suas implicações educacionais: uma pesquisa em etnomatemática. 1979. Dissertação (Mestrado em Educação) Faculdade de Educação, Universidade Estadual de Campinas- UNICAMP. Campinas, 1979.

SCANDIUZZI, P. P. Educação indígena X educação escolar indígena: uma relação etnocida em uma pesquisa etnomatemática. 2000. Tese de doutorado em Educação. Universidade Estadual Paulista, Marília.

SILVA, V. L. O Educando Negro na Escola Pública: Uma perspectiva "Etnomatemática". 2008. Dissertação (Mestrado em Educação). Faculdade de Educação. Universidade de São Paulo FEUSP. São Paulo, 2008.

\section{NOTAS}

${ }^{1}$ Compõem ainda a equipe de pesquisa os professores Admur S. Pamplona (UFMT) e Vanisio L. da Silva (rede de ensino do município de São Paulo), além do graduando bolsista PIBIC/UFMT Fares F. Coelho.

${ }^{2}$ Ressalto, entretanto, a existência de vários conceitos de Etnomatemática, alguns mais amplos e outros mais restritos do que o aqui colocado.

3 O problema das sete pontes de Königsberg data do século XVIII, tendo merecido a atenção do matemático Leonard Euler (1707/1783). Nele se questiona a existência de um caminho que percorra todas as sete pontes sobre o Rio Pregel, passando por elas uma única vez. Hoje, a cidade de Königsberg, localizada no mar Báltico, na Rússia, recebe o nome de Kalininegrad. As pontes que atravessam o rio já não são as mesmas, entretanto o enigma resistiu ao tempo, constituindo um dos problemas clássicos da Teoria dos Grafos.

${ }^{4}$ A sugestão consta da edição especial África da revista Projetos Escolares - ano 3, n. 14.

${ }^{5} \mathrm{Na}$ versão de outros autores citados por ela, o termo teria sua origem nas línguas africanas a partir de um nome que designaria uma dança praticada pela tribo dos Bondos, que vivia, na época da ocupação portuguesa, em território da foz do rio Dande, ao norte de Luanda. Por sua vez, Lima (2008) afirma que a palavra maracatu teria se originado de uma senha combinada para anunciar a chegada de policiais, que vinham reprimir a 
brincadeira. A senha, segundo ela, era anunciada pelos toques dos tambores, emitindo o som: maracatu/maracatu/maracatu.

${ }^{6}$ Grandes tambores.

7 Metalofone de uma ou duas campânulas percutidas por uma vareta de metal.

${ }^{8}$ Instrumento confeccionado com uma cabaça e uma saia de contas.

Recebido: 23/09/2008

Aprovado: 19/03/2009

Contato:

Universidade Federal de Mato (UFMT)

Departamento de Matemática Campus Universitário do Araguaia Grosso

Rodovia MT-100, Km 3,5.

Pontal do Araguaia - Mato Grosso

CEP 78698-000 